\title{
SKILLING FOR THE FUTURE: EVALUATING POST-REFORM STATUS OF "SKILLING PAKISTAN" AND IDENTIFYING SUCCESS FACTORS FOR TVET IMPROVEMENT IN THE REGION
}

\author{
Chamadia, S. ${ }^{1}$ \& Shahid, M. ${ }^{2}$ \\ ${ }^{1}$ Department of Management Science \\ SZABIST University, Karachi, Pakistan \\ ${ }^{2}$ Department of Social Science \\ Hamdard University, Karachi, Pakistan.
}

Correspondence author email: sumairachamadia@gmail.com

Received March 11 ${ }^{\text {th }}, 2018$; Accepted April 22 $2^{\text {nd }}, 2018$

\begin{abstract}
Technical and vocational education plays a pivotal role in mobilizing the wheels of the nation towards development and prosperity and hence it's inevitably important to focus on enhancing the quality of education provided in TVET institutes. Considering the huge skills gap Pakistan has initiated a five-year reform support program in 2011 to transform the current TVET system proposed by National skills strategy. This study hence aims to evaluate the outcomes of the reform support program through field verification and taking inputs from the major stakeholders. The case study approach with single embedded design in which different polytechnic institutions operated under government, private sector and Non-Governmental Organisations were used as unit of analysis sharing the same contextual situations. The findings show that despite getting the support from the international donor agencies and prudently strategized policies, the government has not been successful in achieving the desired outcomes of the reform support program. The success factor identified that could thrive the TVET sector is the strong coalition among all the stakeholders including government, private sector and employers' federation.
\end{abstract}

Keywords: Vocational training, skills gap, educational reform, public-private partnerships

DOI: https://10.30880/jtet.2018.10.01.001 


\section{INTRODUCTION}

Vocational education which was once considered secondary class education compared to general academic or university education has now gained priority specially to resolve the issues of unemployment and for poverty eradication (Marope, Chakroun \& Holmes (2015). The development of skills through technical and vocational education and training has gained much attention at all international development support forums including United Nations Educational Scientific and Cultural Organisation, Organisation for Economic Co-operation and Development and International Finance Corporation in the form of concerned discussion followed by published reports to further strengthen the appendage of action plan required specifically for the developing countries (Symonds et al., 2011). Globally, only those countries have treasured the technological advancement who have technically skilled human resource either their own internal resource or have outsourced from other countries. Many countries in the developing world have now focused towards the reformation of technical and vocational education policies to resolve the labour market imbalances, however there are several issues which will not be addressed by the reforming policies only but it can serve as a starting point to lead towards a better future labour market (Goel \& Vijay, 2017).

According to a report published by IFC the largest global development institution, the world is facing 200 million unemployed people majority of whom are women and youth of the developing nations (Gachassin et al. 2009; Hettige, 2006). The technological advancements around the globe demands the work force with advanced skills to operate the equipment however there is a mismatch in demand and supply of skills needed (IFC, 2013).

Pakistan had approximately 110 million population under 30 age group out of which only $15 \%$ have completed the secondary school education according to national education management information system 2012-2013 (Alif Ailaan, 2014) and the youth with proper technical and vocational education training comprises around 6\%. Reported estimates of unemployment in Pakistan is $8 \%$ which does not pose an alarming situation however the bigger challenge for Pakistan is to tackle the issue of underemployment resulted from the mismatch of the qualification. Unemployment of the work force also includes underemployment ultimately leads to economic, political and social unrest and Pakistan being the second highest country with the maximum share of youth in the population has greater potential towards the violence and social turbulence as a result of rising youth and underemployment (Saeed et al., 2014). Technical and vocational education plays a pivotal role in reducing underemployment by developing employable skills in the youth, enhancing productivity skills and giving access to the high income to the youth who is academically slow and not capable enough to get the managerial degrees.

Recognizing the dilemma that in Pakistan 55\% of the children only enrol and survive till grade $\mathrm{V}$ and the rest $45 \%$ are out of the formal education system, it becomes crucial to integrate the youth into the informal system of technical and vocational education to achieve the socioeconomic sustainability of the nation (United Nations Educational, Scientific and Cultural Organisation [UNESCO], 2015). Further Pakistan is categorized as low-income country hence people with secondary education with technical and vocational education for various trade activities are in more demand than the people with tertiary level of education with managerial 
skills. Technical and vocational education is thus become central to the political reforming policies following the international trend. The funding for the improvement in the TVET in Pakistan has also been supported internationally mainly by European Union to improve the penetration of TVET system in Pakistan (UNESCO-UNEVOC). A five year TVET reform support program has been implemented in 2011 to achieve the proposed reforms highlighted in National skills strategy. A study evaluating the NSS reform support program reports the satisfactory progress in the implementation of the program (Ansari, 2013) however little effort has been done to analyse and evaluate the outcomes of the support program through field scale verification. Hence this study aims to evaluate the results of the reform policy (2011-2016) through field verification and taking inputs from the major stakeholders including the currently enrolled students and the industry.

\subsection{Education structure in Pakistan}

There are two mainstream forms of education in Pakistan; academic and vocational. Academic structure in Pakistan is comprised of three layers: Primary, middle and then Secondary level which is further dissected into Secondary and higher secondary. A student is enrolled at the age of five for the primary level which consist of Grade 1 till 5 (Figure 1), followed by middle section which consists of 6 till 8th and then to secondary from 9th to 10th grade. The next level is the higher secondary which is grade 11th and 12th conducted at the college level (United Nations Educational, Scientific and Cultural Organisation [UNESCO], 2015). A student who is through with all these levels finally make it to the tertiary education or university degree which falls under various categories including natural sciences (medical, engineering etc.), social sciences (business administration, media sciences etc.), humanities and arts and so on.

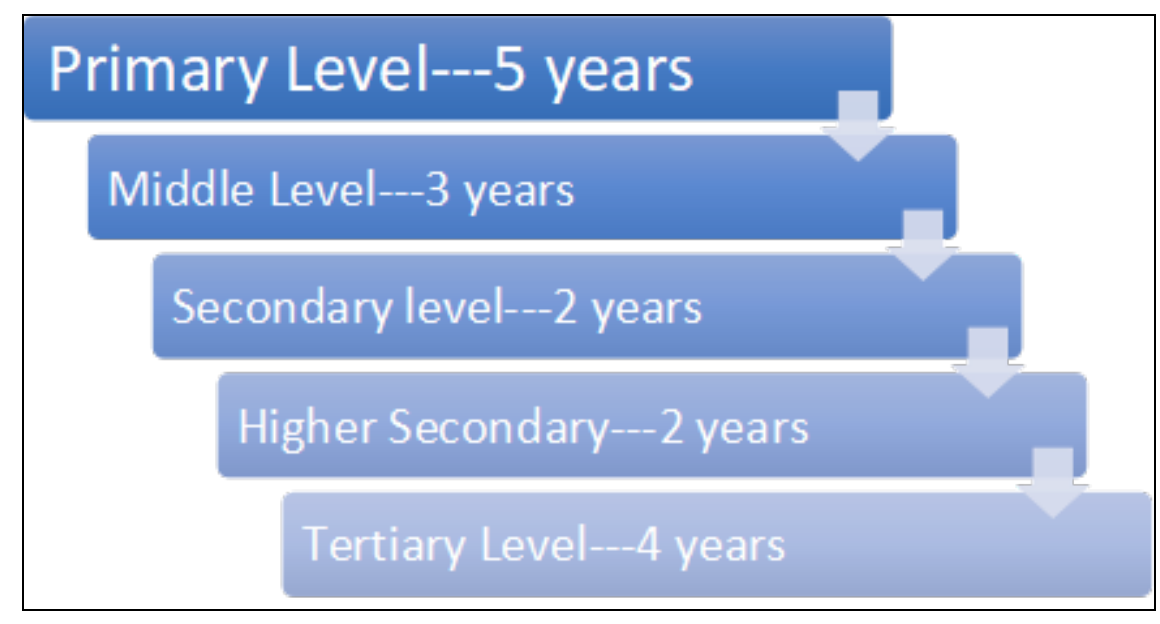

Figure 1: Academic structure in Pakistan

Under formal TVET system courses in various trades with different durations are offered in these technical and vocational institutions ranging from one year certificate to two year diplomas. Further 3 year diplomas in a variety of specializations are also offered in the mono and polytechnic institutes. There is a non-formal system of TVET mainly prevailing by the public sector in Pakistan where technical and vocational centres operate in the apprenticeship system. 
There is huge share of informal sector also which is traditionally known as Ustaad-shagird system where there is no restriction for the enrolment. Anyone with even little or no qualifications can be trained for the required skill of work. Breakup of TVET institutions is shown in Table 1.

Table 1: Province wise breakup of TVET Institutes (NAVTTC, 2017)

\begin{tabular}{lccc}
\hline Province/Region & Public & Private & Total \\
\hline Punjab & 620 & 1197 & 1817 \\
Sindh & 307 & 278 & 585 \\
KPK & 70 & 529 & 599 \\
Baluchistan & 36 & 89 & 125 \\
GB & 26 & 149 & 175 \\
AJK & 48 & 66 & 114 \\
FATA & 33 & 28 & 61 \\
ICT & 37 & 66 & 103 \\
Total & $\mathbf{1 1 7 7}$ & $\mathbf{2 4 0 4}$ & $\mathbf{3 5 8 1}$ \\
\hline
\end{tabular}

\section{RELATED WORKS}

Technical and vocational education plays a pivotal role in mobilizing the wheels of the nation towards development and prosperity and hence it's inevitably important to focus on enhancing the quality of education provided in TVET institutes. To equip the youth with high technical skills undoubtedly results towards the social and economic sustainability. Globally TVET has received international level eminence in recent years (Symonds et al., 2011).

The summit on human resource development by APEC expressed the concern over shortage of technically skilled work force in Asian countries (APEC, 2004). The discussion held addressed the demand driven production of skilled labour force yet dealing with the issue that the institutes providing technical and vocational education have not been successful in preparing the youth in specific fields to facilitate the entrance into the labour market. There is additionally a rising concern except for the quality of vocational educational that the graduates do not enter into the employment or occupational fields in which they were specifically trained which also causes the failure of TVET (OECD, ILO, IBRD, IMF, 2016).

\subsection{Global TVET Reforms}

A number of countries are focusing towards reforming TVET policies to attain high degree skills to achieve social, economic and environmental sustainability. The reforming strategies aim at improving industrial productivity by setting up their TVET models suiting to their technological needs. For example, The German Dual Vocational Training model is viewed as a paragon globally, it combines the class room with on the job training to successfully reduce the 
unemployment level in the country at about $8 \%$ which is much lower when compared to other EU countries of Spain and Greece (OECD, 2012). The German model of technical and vocational education system close coalition among all the stakeholders where the government agencies and ministries look after the instructional quality, private sector bears the training costs for potential work force, employers' federations and trade unions collaborate with the government and private sector and consent to the uniform curriculum and practices to maintain standards (Caillods, 1994). Demand driven trade is widely in use in which employers are equally involved in determining the type of skills to be imparted based on their own industry need analysis. The highlight of this dual system program is the blend of theory and on the job practical experience which instils in the students the soft skills of team work and social integration as well as hard skills of using the advanced technological apparatus (IFC, 2013).

Similarly, there are autonomous bodies operating in Latin America having majority representation from employers who work towards imparting high quality training to the workers as well as students during their leave period (Caillods, 1994). Japan, on the other hand offers a variety of short as well as long duration courses to maintain its continuous improvement programs catering to the needs of trainees to fulfil the requirements of the markets (Alam, 2015).

\subsection{Pakistan's TVET reform support program}

Keeping in view the country's stage of development Lall and Weiss (2004) have posited that the ultimate survival and success of Pakistan lies into its efforts to thrive into high technology and knowledge oriented products to be able to keep pace with the global growth. In this pursuit Pakistan has to adequately strategize the development of skilled workforce meeting the expectations and standards regionally and globally. Recently the capacity of federal and provincial TEVTAS remained failed to produce the demand driven trade skills resulting in the dearth of adequately trained workforce with the requisite set of skills (Shah, 2004; Janjua \& Irfan, 2008). The efforts are required to increase the total factor productivity which is contributing one third towards GDP (Kemal, 2005) which will ultimately cast the positive impact on the human development in terms of education, health and living standards (Janjua \& Irfan, 2008). Besides the lack of contemporary vocational and technical skills, Pakistan also has not been able to instil the soft skills including the cognitive, personal and social skills leading to productivity loss which hurts the exports and dampen the growth in standard of living (Kemal, 2005). Pakistan is in the desperate state of planning and executing the reformation strategies to inculcate the globally demanded skills. In view of this crucial situation there has been a recent paradigm shift in the TVET industry resulted with the collaboration of relevant ministries and national and international consultations. It has been proposed to transform the current TVET system which is based on the curriculum to the competency based training system; which requires the students to acquire the knowledge and skills according to the requirements and standards set by the industries which is assessed before the student joins the workforce or the industry for which the course was designed. Hence the training progress is not time bound rather it depends on the assessments either on the job or off the job or sometimes depend on both the components. This national skills strategy was implemented by the assistance of TVET reform support program launched in April 2010, funded internationally by European Union, Germany and Netherlands. The project was implemented by the joint efforts of NAVTCC and GIZ (German agency for international cooperation). The implementation of the TVET reform system 
was supposed to be conducted by the joint efforts of the NAVTCC at the federal and TEVTAs at the provincial level. It was proposed that the training would be made accessible to disadvantaged regions and women with an integration of informal economy.

\section{RESEARCH METHODOLOGY}

\subsection{Research Design}

The problem under consideration requires the constructivist approach to understand the depth of the complications under the qualitative paradigm. The complete understanding of the underlying causes of the failure of technical and vocational education will only be achieved by taking the perspectives of all the stake holders of this system which will require detailed dialogue with all the stake holders to explore and comprehend the issues pertaining to them which will ultimately be needed to suggest the structural reforms required for the TVET to acquire the desired results and hence the case study approach was used. The case study design is single embedded in which different polytechnic institutions operated under government, private sector and NGOs were used as unit of analysis sharing the same contextual situations. As our context of study is Sindh mainly Karachi all the units operated in Karachi are fronting the same contextual condition whether these are institutes run by public, private or NGOs.

\subsection{Sample}

The study focused on the different polytechnic institutions managed by the government body named Sindh technical education and vocational training association (STEVTA), privately managed institutions and the institutions operated by NGOs in Sindh. Snow ball sampling was used for the research under study where key informants of the industry, senior level bureaucrats, representatives from NGOs and the students and alumni of the TVET institutions were approached. Those industry experts were selected for the interviews who had an experience of over 8 years in the TVET sector. Overall participants were selected in a way that diverse demographic factors in terms of age, gender, locality, previous schooling years, family back ground and work experience could be adequately captured so as to give a complete perspective of the Pakistani youth. Confidentiality of the informants is protected by giving them pseudonyms. These informants were given complete details of the research as well as were disclosed with the potential risks and benefits associated with the research work. The number of sample participants was exhausted based on the saturation point where additional information had no contribution towards the value addition. The sample size includes four TVET experts, twenty currently enrolled students in different departments of publicly managed TVET institutions and eight TVET graduates who learnt the skill but not working in the occupation for which they were trained.

\subsection{Data collection methods}

The current study involves interviews with the current students of various institutions through a semi structured interview protocol. A brief demographic section was included to gather the data regarding the experiences and educational background of the stake holders in the TVET system. The demographic section was comprised of questions regarding age, gender, locality, previous 
schooling years, family back ground and work experience followed by a semi structured questionnaire involving certain probes and prompts to extract information about the stakeholders' perspectives. Interviews were digitally taped after taking approval of the interviewees. Hand written notes were also being taken to supplement the audio recordings and to note the observations which otherwise would not be captured in the digital media.

\subsection{Relevance and validity}

The qualitative research has to be handled scrupulously to avoid any prejudice or influence of the researcher on the interviewee since there is a probability of being subjective as in qualitative research the researcher is actively participating in close contact with the subject and cannot take a detached view. Since it's a multiple source of evidences were used therefore data from various reports prepared by the government of Pakistan on TVET as well as the reports published by the world's renowned organisations such as world bank, UNESCO and IFC will also be collected to verify as well as analyse information extracted through interviews. Similarly interview extracts from the different stakeholders were also compared to ensure the reliability of the information provided during the discourse with the interviewees so as to present the findings with confidence. Further validity and reliability is confirmed by the triangulation method where the findings from the interviews were compared with the official statistics and the observation of the selected sites. Moreover, the verification process also involved the member check where $50 \%$ of the participants were given their feedback as to whether the transcriptions of the interviews convey the same meaning as these were intended. The purpose of the research is to give a voice to the participants without contaminating their beliefs or perspectives.

\section{DATA ANALYSIS}

Our research participants included the industry experts and the currently enrolled students of TVET institutions. The industry experts interviewed included a senior manager working at a private institution of TVET having an experience of around eight years in career counselling and student placement, another industry expert has been a CEO of a skill development institution for past 5 years and has also served as Director of STEVTA. His overall experience in TEVT accumulates to 20 years. Another participant is deputy director in STEVTA and has an experience in the filed for around 12 years. We have also interviewed two experts from the NGOs who also have an extensive experience in TVET. The mode of data collection was predominantly by in person interviews supplemented by the corresponding researcher's notes. Two different protocols of questions were designed to glean out relevant information from two separate sets of participants that is TVET experts and currently enrolled students. Content analysis was done on the various studies, webpages of UNESCO UNEVOC, government published documents and conferences held for TVET. Similarly, thematic analysis is done to capture the emerging recurrent themes. After comparing and ranking different categories various themes and patterns were identified according to the significance and related to the research questions.

Minimal participation of workforce in the TVET

- Lack of awareness regarding the benefits and returns to TVET

- Inferior perception of vocational training in developing countries 
- Socio-economically uncertain background of the targeted communities who are required to participate in the skills learning programs.

Mismatch between the skills taught and the skills demanded in the market

- Lack of adequate Infra-structure of TVET institutions in Pakistan

- Lack of industry ownership

- Relevance

$>$ Lack of access and equitable distribution of TVET institutions for the marginalized and disadvantaged communities.

\subsection{Minimal participation of workforce in the TVET}

The primary issue which popped up in all the interviews was the minimal participation of the work force in TVET which is caused by the lack of awareness of the TVET sector in Pakistan among the population, inferior perception of technical and vocational education and the lack of commitment by socio-economically disadvantaged communities. The findings from the interviews of the students revealed that they mainly live in the vicinity of these institutions, which shows that the institutions or the programs have never been promoted in the society to captivate the attention of the school drop outs or marginalized and disadvantaged factions of the society. The existence of TVET institutions is ubiquitous as the number suggests that 585 institutions are operating in Sindh only but there is little visibility to the end-users of this education system. Since this is considered as an alternative to the academic education, little interest has been shown by the public or private sector to promote TVET and make people aware of its existence and significance to the industry, communities, societies and the economy as a whole.

When asked about whether they can attract people to learn the skills offered, Participant 1 added that:

"We spend 20-30 lac and get 5 admissions only. People are not aware of the institutions in their own locality because there is nothing to promote the institutions."

TVET has never been considered the main stream activity and hence did not achieve a due weightage. The concept of educating a worker is non-existent in Pakistan and hence polishing this segment is not considered important here.

Participant 2 described blue collar jobs as:

"This work is perceived as menial work here in Pakistan unlike first world. The concept of educating and training the work force is limited to managerial level only and the labour force is considered as a muscle worker and not brain worker therefore enhancing the productivity through education and imparting skills is a missing link here."

\subsection{Mismatch between the skills taught and the skills demanded in the market}

The major dilemma in the TVET industry is the mismatch between the skills taught and the skills demanded in the market. The underlying reason is the lack of industry leadership in TVET. Globally the TVET sector is industry driven because its role is inevitable in determining the curriculum and the requisite skills set. Successful implementation of TVET is possible only 
through the industry mapping, and liaison with the industry to get the feedback about the emerging trends, gaps and technologies. However, in Pakistan this is the biggest missing link as industry is not taking the leadership in TVET sector although it is the major beneficiary of this system. According to Mr. Noman:

"There is a trust deficit between Govt. and industry. Industry is getting already what they need through private sector institutions therefore they are complacent."

This was expressed by Participant 2 as:

"Industry do have deep penetration among the workforce they can attract more people towards TVET through their own workforce but they are not showing any interest however they will be ultimate beneficiaries as they will be able to hire trained people on the same wage on which they are hiring unskilled labour."

According to the interview findings there are certain reservations by the industry, they are disinclined because government is not willing to consider the suggestions given by the industry. Further government policies are not very favourable for the industries. Industry would like to come forward and participate if they see that the benefits will be given to them in the form of trained manpower, and when they see the least bureaucratic control. They are reluctant to participate because they do not have the mandate and power to structure the reforms they want to bring about. Another cause of skills gap is the inadequate infra-structure in the public sector managed institutions. While conducting interviews with the students it was brought into notice that majority of the departments in the public-sector institutions are following outdated curriculum, have obsolete equipment and inadequately trained instructors.

One of the students from a public-sector college of technology was of a view that:

"Our teachers have never demonstrated anything related to our field neither they teach us any curriculum. We are told to find everything from the internet."

While discussing about the job opportunities one of the students shared that:

"We have never been exposed to any industrial conditions, never been sent for the internships, similarly there is no career counselling or placement initiatives taken by the institute."

The mentioned points were also covered by Participant 4 in his interview:

"Low attendance, dearth of adequate trainers, nonexistence of equipment to demonstrate for training contribute to the inadequate facilities in the public sector TVET institutes."

Another point which is linked with the above arguments is the lack of relevance in the skills imparted and the skills required in the industry caused by the disconnection between the industry and the institutions. Skills are taught without conducting the market needs analysis or industry mapping and thus the skills imparted are not adequately matched to the skills required in the industry resulting in a mismatch. As one of our industry experts quoted: 
"If you go to work in a place where your job is not needed you will end up doing nothing. For example, what would the world's best electrician do in an area where there is no electricity? Hence relevance plays a fundamental role in TVET."

\subsection{Access and equity}

The problem of access and equity is found to be another hindering factor in the success of TVET. The TVET institutions are unban-centred since we are still in the evolutionary phase of this education system, there are a few institutions in rural areas to develop the skills of the work force. Similarly, the TVET institutes are not adequately catering the needs to empower women through imparting necessary skills to give them opportunity to enter into the work force, similarly there is nothing done to provide equitable chance to the special children, child labour, school drop outs, marginalized communities, in essence the disadvantaged people of the society who are more vulnerable.

According to Participant 5:

"The distribution of institutions is not according to the specific demands. If we give two chapattis to two different people having different appetite; it won't work. We don't need equal distribution we need equitable distribution."

As Participant 4 quoted the same point in this way:

"We are agrarian economy even then we are working on decades old techniques whether it's the seed or pesticides, ploughing or harvesting or irrigation system is not according to the international standards. In the developed countries, same amount of land is producing much higher. But we already have a very big gap in even urban centres so reaching rural areas is near to impossible."

\section{DISCUSSION}

Technical and vocational education and training plays a significant role in promoting the developing nation towards the sustainable economic and social prosperity however there are many challenges and hindrances in a way of successful implementation of the TVET industry in the developing world including Pakistan. This study has attempted to evaluate the five years National Skills Strategy reform support program introduced in 2011 to 2016 through field verification and taking inputs from the major stakeholders including the currently enrolled students and the industry experts. The extracts of the interviews and the content analysis of various reports published by national and international organisation on the education system of Pakistan has revealed several hurdles still prevailing in the TVET sector which preclude the institutions to achieve the desired results. The most emergent problem is the mismatch of skills demanded and skills taught resulting from the minimal participation by the industry. Thus, industrial laid-back attitude and the resulting missing association between the institutions and the industry has been the major impediment in promoting the TVET in the country since the industry 
can provide the most powerful dais to penetrate into the communities where the social media cannot reach. This fact has also been identified in the research conducted by Essel, Agyarkoh, Sumaila \& Yankson (2014) that industry involvement is the key to success for TVET. Further the prerequisite for Technical and vocational education and training is to provide the high quality of training which is possible through state of the art facilities and hands on practice on the equipment, the availability of which is a question mark in the developing countries including Pakistan. The significance of appropriate infra-structure for the successful implementation of TVET in a country is also posited by Dzigbede (2010) and Wahba (2012) whereas Pakistan is in the plight of inadequate infrastructure and competent trainers as evidenced by Nooruddin (2017). The lack of access and equity also emerged as one of the hurdles in affecting the performance of TVET sector that is the institutions are urban-centred with little opportunities for the marginalized communities including the disabled people, women and economically disadvantaged groups. Theses finding are consistent with Ngure (2013) in his research on Korean economy. People in Pakistan like other third world countries are not aware of the benefits of the technical and vocational skills and thus consider this alternative stream of education as menial. This fact is also evident in one of the studies conducted by Agrawal (2012) in India. The statistics revealed in the study by Maiga (2013) also confirms that a much higher proportion of population in developed countries is inclined to get enrolled in technical education as compared to developing countries which in return makes them as the most buoyant economies of the world.

\section{CONCLUSION AND RECOMMENDATION}

\subsection{Conclusion and implications}

Despite getting the support from the international donor agencies and the strategies at the national level, the government has not been successful in achieving the desired outcomes of the reform support program. The impediments that restrain the successful implementation of TVET processes in the country include the lack of adequate infra-structure in the TVET institutions, outdated curriculum, obsolete equipment, inexperienced trainers and skills gap arising out of missing linkage between the industries and the institutions. The absence of explicitly defined career trajectories in the vocational occupation makes it more difficult to achieve the results from the TVET sector. Further little attention has been given by the government to spread the awareness regarding the importance and benefits of TVET as well as the facilities and institutions available for the technical and vocational education in the country. Lack of access to the institutions by the deprived and marginalized communities also adds to the obstacles in promoting this alternative stream of education. The primary tasks confronted by the economy of Pakistan are to provide the employable skills to an approximate of 7 million people who are entering the labour market every year, to upgrade the skills of existing workforce to commensurate with the changing technology and to intervene to organize the Informal sector. The competence based training (CBT) has recently been introduced which will focus on accreditation of the training conducted in the informal sector. CBT will help in the vertical mobility of the workers by awarding certificates to the candidates trained under the informal system. This study will serve as a lens to the policy makers, the concerned ministries and the federation of Pakistan chamber of commerce and industry to discern and analyse the impediments existent in the TVET sector to strategize accordingly and to take necessary steps 
towards the social sustainability. The unofficial data estimates that there is approximately 5.5 million work force operating in Karachi city only; if the concerned authorities manage to enhance their productivity even in micros or at granular level the benefits will ultimately be translated into the higher earnings which would lead to incentivize the labour to undertake vocational qualification, rising returns on investments, increased operational leverage and improved productivity thus rendering the economic benefits to the individual, enterprise and the societal level. Further the findings of this research are useful for the concerned organisations to decipher the outcomes or the progress of the executed intervention. This study also suggests in general that despite having allocated the budgets in the required area and adequate planning if the execution of the intervention is not monitored at every step, it becomes very difficult to achieve the desired results.

\subsection{Recommendations}

In order to make sustainable progress Pakistan needs to focus on building skills of youth in accordance with local and international markets so that it could lead them to decent and standard living environment and investment in HR according to the model presented in the theoretical framework is the only solution to the problems faced in the country. There are many structural reforms that are required to be introduced in the country to successfully implement the TVET system and transfer the benefits to the end users. Following are the success factors which were identified during the research study and are found to be essentially required to bring about a paradigm shift in the TVET sector:

- Public private partnership

- Industry leadership

- Changing position of government from administrator to facilitator

The most crucial step towards effective reformation is the complete revamping of TVET in Pakistan which includes up gradation of the curriculum, bringing in the modern and state of the art technologies in the institutions, updated equipment, adequately experienced trainers and the introduction of social competence as a proper segment of TVET system. It's extremely important for the Industry to take the leadership in promoting the TVET by developing a strategic partnership between the industry and institutions. Developing strong linkages and working relationships with the industry by providing meaningful role to industry in development, management and assessment of training is inevitable to the reform success. 


\section{References}

Agrawal, T. (2012). Vocational education and training in India: Challenges, status and labour market outcomes. Journal of Vocational Education and Training, 64(4), 453-474.

Alam, N. (2015). The role of technical vocational education and training in human development: Pakistan as a reference point. European Scientific Journal, ESJ, 11(10).

Alif Ailaan. (2014). 25 million broken promises: The crisis of Pakistan's out-of-school children. Retrieved from http://www.alifailaan.pk/broken_promises

APEC (2004), Communiqué: Fourth APEC Science Ministers' Meeting. Christchurch, New Zealand: Asia-Pacific Economic Cooperation.

Ansari, B., \& Wu, X. (2013). Development of Pakistan's technical and vocational education and training (TVET): An analysis of skilling Pakistan reforms. Journal of Technical Education and Training, 5(2).

Caillods, F. (1994). Converging Trends amidst Diversity in Vocational Training Systems. International Labour Review 133 (2):241-257.

Dzigbede, F. K. K. (2009). Challenges in the administration of technical Vocational education and training in the Ghana Education Service. (Unpublished thesis). University of Cape Coast.

Essel, O. Q., Agyarkoh, E., Sumaila, M. S., \& Yankson, P. D. (2014). TVET Stigmatization in Developing Countries: Reality or Fallacy. European Journal of Training and Development Studies, 1(1), 27-42.

Gachassin, Marie, Boris Najman, and Gaël Raballand. 2009. Roads impact on poverty reduction. A Cameroon case study.

Goel, D., \& Vijay, P. (2017). Technical and vocational education and training (TVET) system in India for sustainable development.

Hettige, H. (2006). When do rural roads benefit the poor and how? An in-depth analysis based on case studies. Asian Development Bank.

International Finance Corporation (IFC). (2013). Assessing private sector contributions to job creation and poverty reduction.

Janjua, Y., \& Irfan. M (2008). Situation analysis to support the programme design process for National Skills Strategy of the Islamic Republic of Pakistan.

Kemal, A. R. (2005). Skill development in Pakistan. The Pakistan Development Review, 44(4), 349-357.

Lall, S., \& Weiss, J. (2004). Industrial Competitiveness: the challenge for Pakistan. Asian Development Bank Institute-Pakistan Resident Mission Research Paper, Islamabad.

Maiga, E. (2013). Making skills development work for economic transformation in Africa: Demystifying the suit and de-stigmatizing vocational and technical education. Retrieved from http://acetforafrica.org/makingskills developmentwork- for-economic-transformation-in-africa-demystifying-the-suit-and-destigmatizingvocational-and-technical-education.

Marope, P. T. M., Chakroun, B., \& Holmes, K. P. (2015). Unleashing the potential: transforming technical and vocational education and training. UNESCO Publishing.

Mykerezi, P. K. (2003). The potential contribution of vocational and technical education to the future socialeconomic development of Albania (Doctoral dissertation, Virginia Tech).

Ngure, S. W. (2013). Stakeholders' perceptions of technical, vocational education and training: the case of Kenyan micro and small enterprises in the motor vehicle service and repair industry. (Doctoral thesis) Edith Cowan University. Retrieved from http://ro.ecu.edu.au/theses/597.

Nooruddin, S. (2017). Technical and Vocational Education and Training for Economic Growth in Pakistan. Journal of Education and Educational Development, 4(1), 130-141.

Organisation for Economic Co-operation and Development (OECD) International Labour Organisation (ILO); World Bank (IBRD); International Monetary Fund (IMF). (2016). Enhancing employability: report prepared for the G20 Employment Working Group.

Pakistan: World TVET Database - Country Profiles. (2013, November 06) Retrieved from http://www.unevoc.unesco.org/go.php?q=World+TVET+Database\&lang=en\&ct=PAK

Saeed, Y., Hirashami, M., Khathran, R. N., \& Sheikh, H. B. (2014). Law as Means of Preventing Violence among Youth through Social Control Mechanism. Pakistan Vision, 15(1), 100.

Shah, I. H. (2004). Problems and prospects technical education in Pakistan. University of Arid Agriculture, PhD Thesis, Murree Road, Rawalpindi, Pakistan. 
Symonds, W.C., Schwartz, R.B. and Ferguson, R. (2011), Pathways to Prosperity: Meeting the Challenge of Preparing Young Americans for the 21st Century, report, Pathways to Prosperity Project, Harvard Graduate School of Education.

Wahba, M. (2012). Technical and vocational education and training (TVET) challenges and priorities in developing countries. Retrieved February, 11, 2012.

United Nations Educational, Scientific and Cultural Organisation (UNESCO). (2015). "Education for All 2015 National Review Report: Pakistan"

United Nations Educational, Scientific and Cultural Organisation UNESCO (2010), World Data on Education, 7th Edition, 2010/11: Ghana, United Nations Educational, Scientific and Cultural Organisation, Paris.

World Bank (2012). World Development Report 2013: Jobs. Washington DC: The World Bank. 